\title{
A utilização de jogos como ferramenta de aprendizagem do ensino da disciplina de materiais betuminosos
}

\author{
Letícia Sousa de Oliveira $^{1}$, Suelly Helena de Araújo Barroso ${ }^{2}$, Jorge Barbosa Soares ${ }^{3}$ \\ 1Universidade Federal do Ceará, Brasil, leticia.Itc@gmail.com \\ 2Universidade Federal do Ceará, Brasil, suelly@det.ufc.br \\ 3Universidade Federal do Ceará, Brasil, jsoares@det.ufc.br
}

\section{Recebido:}

23 de abril de 2018

Aceito para publicação:

25 de julho de 2018

Publicado:

31 de dezembro de 2019

Editor de área:

Francisco Thiago Aragão

\section{Palavras-chaves:}

Ensino,

Aprendizagem,

Jogos,

Engenharia Civil.

\section{Keywords:}

Teaching,

Learning,

Games,

Civil Engineering.

DOI:10.14295/transportes.v27i4.1664

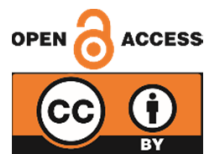

\begin{abstract}
RESUMO
Os jogos em sala de aula servem como atividade para melhorar e incentivar a aprendizagem do aluno, tornando-o mais ativo em sala e permitindo uma melhor fixação do conhecimento transmitido. Este artigo propõe a utilização de jogos como ferramenta de aprendizagem da disciplina de Materiais Betuminosos, do Curso de Engenharia Civil da Universidade Federal do Ceará para proporcionar aos alunos maior absorção do conhecimento. Foi proposto um jogo de tabuleiro em que os temas abordados foram asfaltos, asfaltos modificados, emulsões asfálticas, agregados e misturas asfálticas. Para avaliar o estilo de aprendizagem dos alunos e professor foi aplicado o Índice de Estilos de Aprendizagem e para analisar a eficiência do jogo foi desenvolvido um questionário baseado nas competências e habilidades exigidas pelo Conselho Nacional de Educação. Verificouse o potencial do jogo em proporcionar motivação, aprendizagem, armazenamento do conhecimento e o desenvolvimento de algumas habilidades requeridas na área de Engenharia Civil.
\end{abstract}

\begin{abstract}
Classroom games serve as an activity to enhance and encourage student learning, making them more active in class and allowing better learning and knowledge transmission. This article proposes the use of games as a learning tool for the course of Bituminous Materials of the Civil Engineering undergraduate degree at Federal University of Ceará, with the objective of providing students with an enhanced learning experience. It was proposed a board game in which the topics addressed were asphalts, neat and modified, asphalt emulsions, aggregates, and asphalt mixtures. To evaluate the learning style of students and faculty, it was applied the Index of Learning Styles, and a questionnaire was developed based on the skills and abilities required by the National Council of Education to evaluate the effectiveness of the game. It was verified the potential of the game in providing motivation, learning, storage of knowledge and the development of some skills required in the area of Civil Engineering.
\end{abstract}

\section{CONSIDERAÇÕES INICIAIS}

Com o avanço da tecnologia de informação, ferramentas inovadoras entraram no campo da educação, como a introdução da informática, o uso de multimídias, ensino à distância, aplicativos em celulares de jogos educacionais, etc. Apesar desses avanços, os professores encontram dificuldades em sala de aula para inserir as novas práticas pedagógicas que motivem mais os alunos e ajudem a formar profissionais com os atributos exigidos na prática profissional.

Nesse contexto, é importante que o docente busque novas metodologias de ensino para melhorar a aprendizagem em sala de aula, a aplicação prática da teoria, o exercício do pensamento crítico, da criatividade e do espírito de liderança. As técnicas de ensino tradicionais, baseadas 
no processo em que apenas o professor expõe o conhecimento, podem ser alinhadas e utilizadas em conjunto com ferramentas inovadoras disponíveis que auxiliam no processo de educação a fim de incentivar os alunos a serem mais ativos em sala. Dentre as metodologias inovadoras deste século, destacam-se a Sala de Aula Invertida (Inverted Classroom), Aprendizagem Baseada em Problemas (Problem-Based Learning), Aprendizagem Baseada em Projetos (Project-Based Learning) e Aprendizagem Baseada em Jogos (Game Based Learning -GBL).

Este trabalho tem como objetivo analisar, por meio de um estudo de caso, a utilização de jogos como instrumento de ensino para alunos da graduação no curso de Engenharia Civil, proporcionando-os aprendizagem, diversão e interação. Percebendo-se a importância do uso do GBL no processo de ensino-aprendizagem, foram utilizados jogos como instrumentos de ensino/aprendizagem da disciplina de Materiais Betuminosos do curso de Engenharia Civil da Universidade Federal do Ceará (UFC). A elaboração do jogo ocorreu no segundo semestre de 2017, sendo que a referida disciplina é optativa e, naquele momento, havia 10 alunos matriculados, valendo notar que há uma homogeneidade entre os alunos que buscam anualmente essa disciplina no que diz respeito à nota média, semestre em curso quando da matrícula, presença em iniciação científica, estágio ou monitoria.

\section{FUNDAMENTAÇÃO TEÓRICA}

O uso de jogos é uma ferramenta inovadora e uma das possibilidades de incentivar e testar o conhecimento adquirido em sala de aula. A fim de melhor compreender como os jogos podem se tornar uma ferramenta didática de auxílio é necessário entender como ocorre à aprendizagem baseada na utilização desses e como a identificação das preferências de aprendizagem auxilia no planejamento das atividades a serem conduzidas em sala de aula.

\subsection{Aprendizagem Baseada em Jogos}

Os jogos e as brincadeiras estão sempre presentes em todas as fases da vida, sendo muito valiosos no processo de aprimoramento do conhecimento, pois possibilitam o desenvolvimento de competências no âmbito da comunicação, relações interpessoais e liderança (Souza-Lomba et al., 2010).

Game Based Learning (GBL) é uma estratégia de ensino e aprendizagem através de jogos. As simulações e os jogos didáticos são instrumentos que podem auxiliar o processo de ensino de diversas áreas (Ammar e Wright, 1999; Vasconcelos et al., 2012; Song et al., 2012; Verschueren e Mardjan, 2015), inclusive na engenharia (Au et al., 1969; Balceiro et al., 2003; Baker et al., 2005; Sacks et al., 2007; Ozelkan e Galambosi, 2009; Lima e Melo, 2013; García et al., 2017). Portanto, os jogos educativos podem promover a aprendizagem e auxiliar na construção do conhecimento. Os jogos podem, por exemplo, ajudar a desenvolver habilidades profissionais, obter níveis diferentes de experiência pessoal e social, enriquecer a personalidade e a criatividade, bem como possibilitar a construção da autoconfiança dos alunos. Percebe-se que os discentes, ao jogar, se sentem mais livres para criticar e argumentar, resultando em um aluno mais ativo em sala de aula (D’Ambrósio, 1989; Moura, 1991; Lane, 1995; Silveira e Barone, 1998). Assim, os alunos podem ser estimulados a sair do consumo de informações prontas, quando são expostos somente aos métodos tradicionais de educação, para serem alunos ativos e participativos no processo de construção do ensino, conhecimento e aprendizagem.

Braga et al. (2007) afirmam que o jogo envolve variadas ações intimamente ligadas com os sentimentos, entre eles a alegria, a frustração, a confiança e a apreensão. 0 jogo educativo deve 
ser elaborado de forma que desenvolva o envolvimento emocional e proporcione ao indivíduo espontaneidade, mas sem perder o foco no aprendizado. É importante ressaltar que os jogos não devem ser vistos como única estratégia didática de aquisição de conhecimento, uma vez que por si só não garantem a aprendizagem, sendo suportes de ensino para o professor (Zanon et al., 2008).

Apesar das vantagens em se utilizar o GBL em sala de aula, alguns cuidados devem ser levados em consideração na escolha do jogo para que se possa garantir a essência do jogo e do processo educativo. Quando essas atividades são mal utilizadas, há o risco de dar ao jogo um caráter puramente aleatório e o tempo gasto pode sacrificar o ensino de outros conteúdos (Soares, 2008). É fundamental que o jogo atinja a proposta de ser útil no processo educacional e para isso o mesmo deve ser interessante, desafiador, permitir a participação de todos os alunos e estimular que o próprio discente seja capaz de avaliar seu desempenho em absorver os conhecimentos expostos.

Lima e Melo (2013) abordaram a elaboração e aplicação de nove jogos educativos para auxiliar na aprendizagem da disciplina Estradas e Transportes do curso de Engenharia Civil. Dentre os jogos aplicados, sete são jogos de tabuleiro, um é de jogo da memória e o outro um jogo de perguntas e respostas. A análise realizada permitiu concluir a eficácia do uso dos jogos quanto à capacidade de proporcionar o processo criativo, a prática por meio de um cenário lúdico, diversão, interação entre os alunos e professor e a absorção, bem como o aprimoramento do conhecimento.

Braghirolli (2014) propôs o uso de um jogo educacional computacional como uma alternativa no ensino do primeiro ano do curso de graduação em Engenharia de Produção. Por meio de um questionário, avaliou-se a contribuição do jogo para a aprendizagem e motivação dos alunos. Foi observado que o uso de jogos possibilitou uma maior interação entre professor e aluno, promoveu aprendizagem, motivação e resultou em boa aceitação.

\subsection{Estilos de Aprendizagem}

O Índice de Estilos de Aprendizagem (Index of Learning Styles - ILS) classifica as preferências de aprendizagem de acordo com quatros dimensões do Modelo de Estilos de Aprendizagem formulado por Felder e Silverman (1988). A primeira dimensão avalia como ocorre o processo da informação, podendo ser de forma ativa ou reflexiva. A segunda dimensão se refere a que tipo de informação o aluno percebe, classificada como sensorial ou intuitiva. A terceira dimensão analisa qual canal sensorial é o mais utilizado, o visual ou o verbal. A quarta dimensão avalia como ocorre o avanço no entendimento do assunto, de forma sequencial ou global. Para cada dimensão, o aluno ainda pode ser classificado como leve, moderado ou forte, portanto o ILS fornece uma indicação de possíveis pontos fortes e tendências dos alunos. O questionário do ILS é composto de 44 itens e cada item contém apenas 2 opções, sendo 11 itens pertencentes a cada uma das 4 dimensões. A diferença entre as quantidades de respostas referentes a cada estilo dentro das dimensões permite conhecer a intensidade dessa preferência, podendo ser considerada leve, moderada ou forte. Kuri et al. (2006) desenvolveram um trabalho de pesquisa com o objetivo de explorar e avaliar alternativas pedagógicas, para complementar a metodologia usualmente utilizada na disciplina de Planejamento de Transportes do Curso de Engenharia Civil da EESC/USP, fazendo o uso de recursos da hipermídia e dos modelos de estilos de aprendizagem. Os resultados alcançados demonstraram que as alternativas consideradas, como o uso 
do ILS, contribuíram para o aprimoramento da metodologia tradicional e promoveram resultados positivos para o aprendizado na disciplina.

Silva Junior et al. (2013) identificaram os estilos de aprendizagem dos alunos e professores envolvidos em disciplinas de Infraestrutura de Transportes da Universidade Estadual de Londrina. 0 questionário utilizado foi o ILS e os resultados permitiram a identificação de incompatibilidades entre as preferências de aprendizagem dos grupos envolvidos e as estratégias adotadas pelos docentes para o ensino. A identificação dos estilos de aprendizagem dos alunos e instrutores se apresenta como potencial para melhorar o processo ensino/aprendizagem em sala de aula.

Em geral, os estudantes de Engenharia são: (i) predominantemente ativos, pois gostam de lidar com a informação através da experimentação; (ii) sensoriais, já que possuem maior facilidade de aprender pela observação; (iii) visuais, uma vez que gostam mais de informações gráficas que contenham figuras, diagramas, esquemas, filmes e fluxogramas e (iv) sequenciais, pois preferem a matéria disposta de forma progressiva partindo-se do específico para o geral (Felder e Silverman, 1988; Cury, 2000).

Assim, através das leituras realizadas, verificou-se que o ILS tem sido bastante utilizado em pesquisas educacionais, principalmente nas áreas de engenharia e de ciências (Cury, 2000; Pereira et al., 2004; Kuri, 2004; Belhot et al., 2005; Pereira, 2005; Kuri et al., 2006; Siqueira et al., 2012; Siqueira et al., 2013; Silva Junior et al., 2013).

\section{ESTUDO DE CASO}

O projeto proposto consistiu de um jogo de tabuleiro, intitulado de MasterPav, no qual os alunos foram divididos em grupos de até 3 pessoas, sendo realizadas perguntas relacionadas à disciplina e ganhando o grupo que atingisse primeiro a linha de chegada. 0 jogo, as perguntas e suas regras foram elaborados a partir de sucessivas discussões e reformulações para que se chegasse a um jogo divertido e adequado para a disciplina. 0 tabuleiro possui 53 casas, das quais 16 eram de nível fácil, 24 de nível médio e 13 de nível difícil, conforme indicado na Figura 1. Contou-se ainda com um dado; pinos de cores diversas; cartas com perguntas, divididas em nível fácil, médio e difícil e um cronômetro (ver Figura 2).

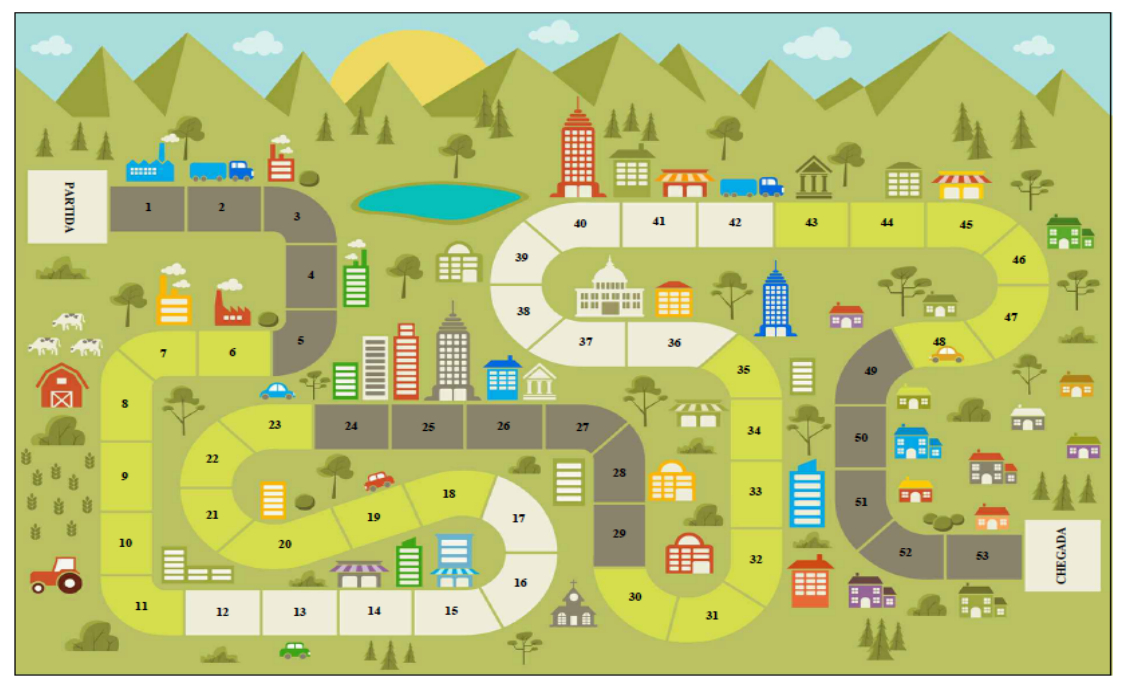

Figura 1: Tabuleiro do jogo adaptado de https://gogomedia.pl/blog/backend/nowosci-w-php-7-cz-2-definiowanietablic-jako-stalych/, 2017 
As casas de cores cinzas correspondem ao nível fácil, as verdes ao nível médio e as brancas ao nível difícil. Ao cair em uma das casas, o grupo deveria responder corretamente à pergunta de uma das cartas da cor correspondente, havendo o tempo de 30 segundos para a resposta, a contar do término da leitura da pergunta. 0 tempo para resposta foi escolhido de forma a permitir que os alunos formulassem suas respostas dentro de um período considerado razoável e com segurança ao responder. A carta escolhida continha a premiação ou a punição de acordo com a resposta da equipe (ver Tabela 1 ).

Tabela 1: Premiação e punição contidas nas cartas

\begin{tabular}{ll}
\hline Premiação & Punição \\
\hline Avance 1 casa & Fique uma rodada sem jogar \\
Avance 2 casas & Fique duas rodadas sem jogar \\
Avance 3 casas & Permaneça no seu lugar \\
Avance 4 casas & Volte 1 casa \\
Avance 5 casas & Volte 2 casas \\
Permaneça no seu lugar & Volte 3 casas \\
& Volte 4 casas \\
& Volte 5 casas \\
\hline
\end{tabular}

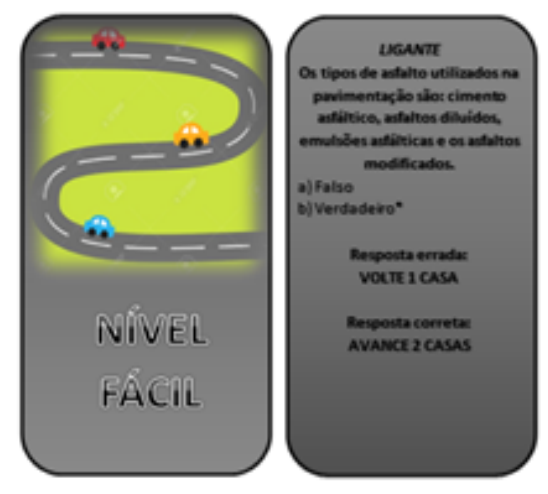

(a)

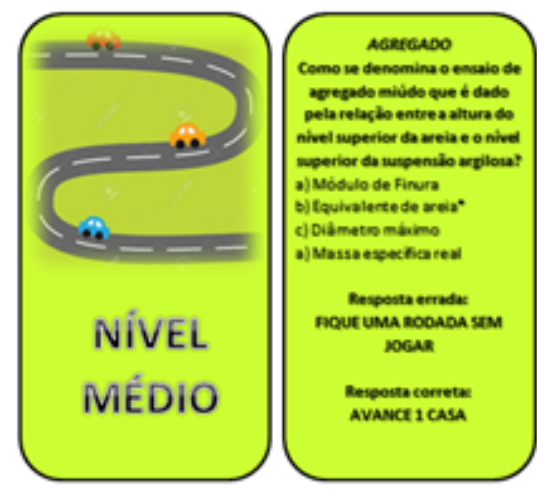

(b)

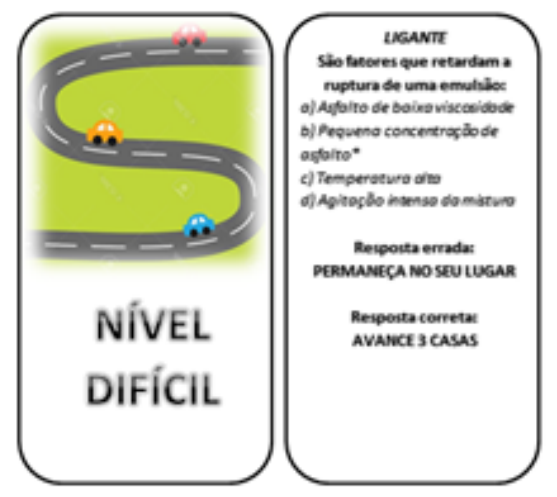

(c)

Figura 2: (a) Carta de nível fácil; (b) Carta de nível médio; (c) Carta de nível difícil

Por se tratar de um jogo com o objetivo de fazer uma revisão que antecedesse a prova e fixar os conteúdos abordados, a turma foi avisada uma semana antes sobre a aplicação do jogo em sala de aula para que os alunos estudassem com antecedência. A Figura 3 mostra momentos durante a aplicação do jogo MasterPav na turma. Percebeu-se que os alunos se envolveram com o jogo, unindo o divertimento com o momento de tirar dúvidas a respeito de alguns conteúdos.

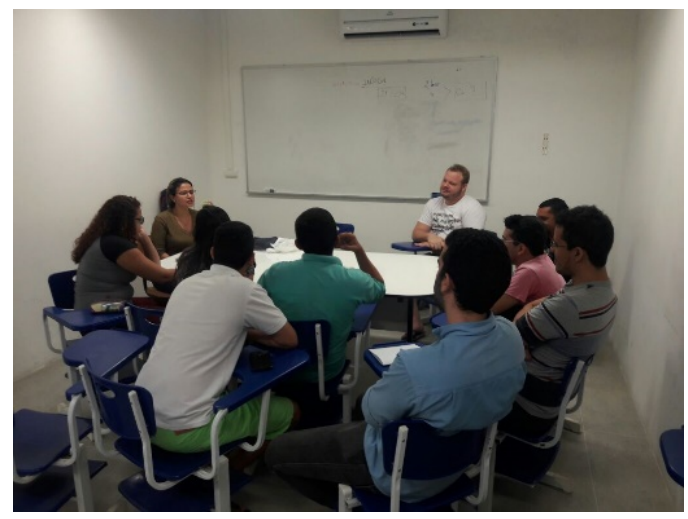

Figura 3: Momento de aplicação do jogo MasterPav 
A avaliação da atividade didática foi realizada por meio da aplicação de dois questionários. Primeiramente, foi aplicado o formulário do ILS, desenvolvido por Felder e Soloman (1991), a fim de detectar os estilos de aprendizagem dos alunos conforme os seguintes aspectos: (i) como o aluno processa a informação; (ii) que tipo de informação o aluno percebe; (iii) qual o canal sensorial mais utilizado e (iv) como se dá o avanço no entendimento do assunto.

A segunda avaliação consistiu na elaboração e aplicação de outro questionário com perguntas relacionadas diretamente ao jogo sobre os seguintes aspectos: (a) aprendizagem; (b) motivação; (c) processamento e armazenamento do conhecimento e (d) desenvolvimento de habilidades relacionadas à Engenharia conforme as diretrizes curriculares definidas pelos órgãos de educação.

O Conselho Nacional de Educação instituiu Diretrizes Curriculares Nacionais do Curso de Graduação em Engenharia (2001) nas quais foram definidas as exigências relacionadas às competências e às habilidades gerais que devem ser intrínsecas na formação do engenheiro. Dentre essas habilidades estão: aplicar os conhecimentos à engenharia; interpretar resultados; identificar, formular e resolver problemas de engenharia; desenvolver e/ou utilizar novas ferramentas e técnicas; comunicar-se eficientemente nas formas escrita, oral e gráfica; atuar em equipes multidisciplinares; compreender e aplicar à ética e responsabilidade profissionais.

Tabela 2: Aspectos analisados no jogo através das questões

\begin{tabular}{|c|c|}
\hline Aspectos analisados no jogo & Questões \\
\hline \multirow{3}{*}{ (a) Motivação } & 1. O quanto completar os exercícios do jogo deu a você um sentimento de realização? \\
\hline & 2. O quanto você estudou para obter bons resultados no jogo? \\
\hline & 3. O quanto você se sente estimulado a revisar um conteúdo a partir do jogo aplicado? \\
\hline \multirow{3}{*}{ (b) Aprendizagem } & $\begin{array}{l}\text { 4. Você se sentiu preparado para responder as perguntas do jogo a partir do conhecimento } \\
\text { adquirido em sala de aula? }\end{array}$ \\
\hline & 5. Você aprendeu conteúdos com o jogo que foi surpreendente ou inesperado? \\
\hline & 6. Você acha que o jogo ajudou para fixar conteúdos ministrados em sala de aula? \\
\hline \multirow{3}{*}{$\begin{array}{l}\text { (c) Processamento e armazena- } \\
\text { mento do conhecimento }\end{array}$} & $\begin{array}{l}\text { 7. A interação entre os participantes ajuda no processamento e armazenamento de infor- } \\
\text { mações adquiridos durante o jogo? }\end{array}$ \\
\hline & $\begin{array}{l}\text { 8. Após jogar, o quanto você consegue lembrar as informações relacionadas ao assunto } \\
\text { apresentado no jogo? }\end{array}$ \\
\hline & 9. Após jogar, você consegue compreender melhor o assunto apresentado no jogo? \\
\hline \multirow{3}{*}{ (d) Habilidades } & 10. Você sentiu que estava colaborando com outros colegas? \\
\hline & $\begin{array}{l}\text { 11. Após jogar, você conseguiu aplicar melhor o tema abordado no jogo com a sua profis- } \\
\text { são? }\end{array}$ \\
\hline & $\begin{array}{l}\text { 12. Você se sentiu capacitado para aplicar, identificar, formular e resolver problemas a res- } \\
\text { peito dos assuntos abordados? }\end{array}$ \\
\hline
\end{tabular}

Para se obter uma avaliação qualitativa do jogo, optou-se por utilizar notas numa escala de 2 a 10, na qual 2 significa péssimo, 4 ruim, 6 regular, 8 bom e 10 ótimo. Para que a avaliação não se tornasse longa e cansativa para os alunos, um total de apenas 12 perguntas foram elaboradas. Na Tabela 2 estão apresentados os aspectos analisados em cada pergunta. Dentre as perguntas elaboradas, as 3 primeiras se referem a como os alunos se sentem motivados com o uso do jogo em sala, as perguntas de 4 a 6 se referem à aprendizagem adquirida anteriormente em sala, as perguntas de 7 a 9 são referentes ao processamento e armazenamento do conhecimento e as perguntas de 10 a 12 referem-se às habilidades e competências relacionadas à Engenharia de acordo com as Diretrizes Curriculares Nacionais do Curso de Graduação em Engenharia. 


\section{RESULTADOS E DISCUSSÕES}

\subsection{Quanto aos estilos de aprendizagem dos alunos e professor}

Primeiramente, foi aplicado um questionário, o ILS, antes do início do jogo, para detectar os estilos de aprendizagem de cada aluno. Esse questionário foi aplicado e respondido pelos 10 alunos e também pelo professor, para que também fosse possível identificar qual o seu estilo de aprendizagem.

A Figura 4 mostra as porcentagens obtidas a partir das respostas atribuídas pelos alunos e pelo professor para o aspecto de como o conhecimento é processado. Conforme os resultados, $90 \%$ dos alunos processam o conhecimento de maneira "ativa", dos quais $30 \%$ são de forma leve e $60 \%$ de forma moderada, enquanto que o professor processa de forma "ativa" forte. Esses alunos que processam o conhecimento de maneira "ativa" tendem a compreender e reter melhor as informações participando ativamente da realização da atividade e trabalham melhor em grupo do que sozinhos.

A respeito do tipo de informação que o aluno percebe, elaborou-se a Figura 5. Observou-se que $90 \%$ dos alunos percebem as informações de maneira sensorial, sendo $30 \%$ de forma leve e $60 \%$ de forma moderada. 0 professor também percebe as informações de maneira sensorial, porém a sua percepção se dá de forma forte. Assim, grande parte dos alunos é mais prática e cuidadosa, preferindo as informações através de fatos e dados. Apenas 10\% gostam de inovação na hora de perceber a informações, ou seja, preferem evitar atividades que dependem de memorização, rotineiras ou repetitivas.

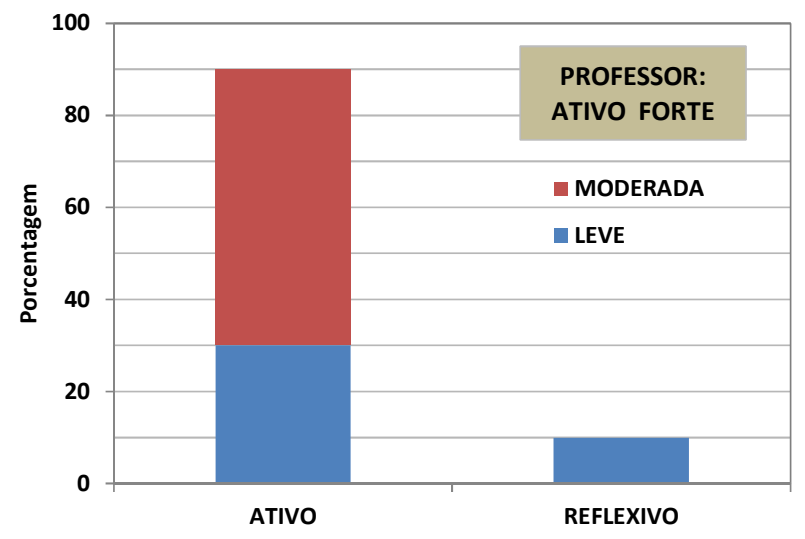

Figura 4: Forma como o aluno e o professor processam o conhecimento

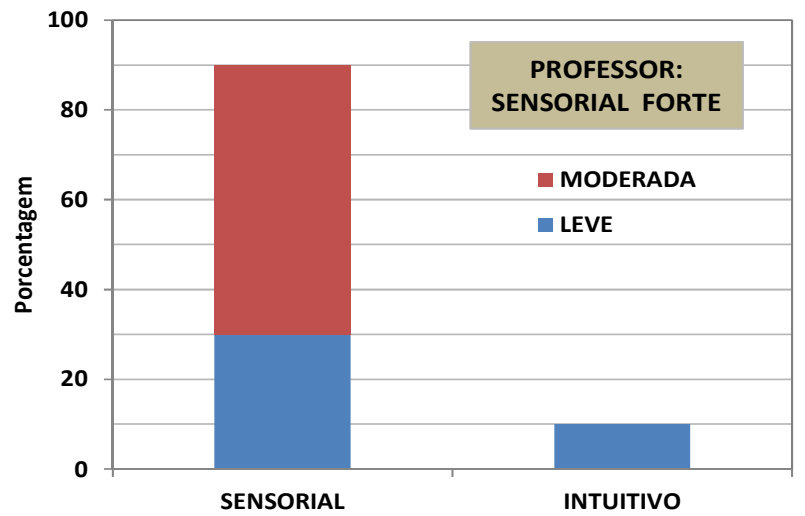

Figura 5: Tipo de informação que o aluno e o professor percebem 
Em relação ao canal sensorial mais utilizado, $60 \%$ dos alunos utilizam a visão como seu principal canal sensorial e 40\% utilizam a forma verbal, como indicado na Figura 6. Dos 60\%, 40\% utilizam o canal verbal de maneira leve e $20 \%$ de maneira moderada, enquanto que o professor utiliza esse mesmo canal de forma forte. As pessoas que usam o canal sensorial visual capturam mais as informações através de gráficos, quadros, figuras, filmes e demonstrações, enquanto aquelas que utilizam o verbal preferem material escrito, falado ou até mesmo por meio de fórmulas.

Quando se verifica como se dá o avanço no entendimento do assunto visto em sala de aula (ver Figura 7) observa-se que 70\% dos alunos são sequenciais e tendem a seguir caminhos mais lógicos e graduais na solução de problemas, e 30\% dos alunos são globais e, portanto, possuem seu foco na síntese, no pensamento sistêmico e não na linearidade, tendendo assim a aprender através de saltos intuitivos. Neste item, novamente o professor apresentou uma tendência forte para avançar no seu conhecimento através da forma sequencial.

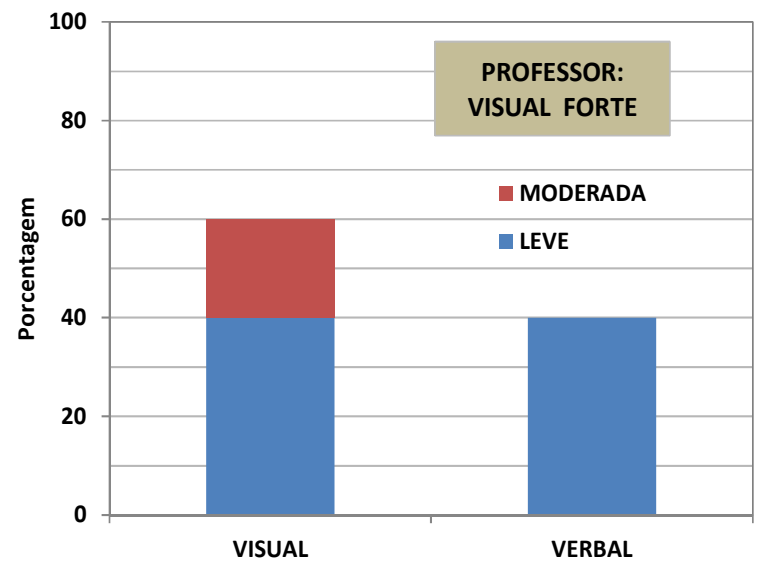

Figura 6: Canal sensorial mais utilizado pelo aluno e pelo professor

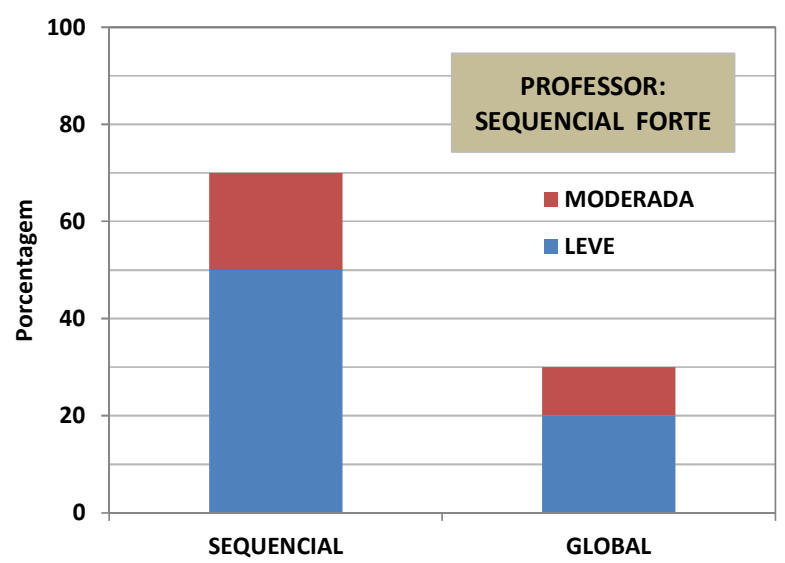

Figura 7: Avanço no entendimento do assunto pelo aluno e pelo professor

A fim de realizar uma melhor análise dos dados foi utilizada a estatística descritiva para permitir uma visão global da variação dos resultados, conforme apresentado na Tabela 3. Os valores da média sugerem a tendência dos quatros índices medidos. Os valores positivos indicam destaque para os estilos ativo, sensorial, visual e sequencial, enquanto que os valores negativos indicam destaque para os estilos reflexivo, intuitivo, verbal e global. 
Tabela 3: Estatística descritiva dos estilos de aprendizagem

\begin{tabular}{llllll}
\hline Estilos & Mínimo & Máximo & Mediana & Média & Desvio padrão \\
\hline Ativo/Reflexivo & -1 & 9 & 4,5 & 4,4 & 3,2 \\
Sensorial/Intuitivo & -1 & 9 & 4,5 & 4,4 & 3,2 \\
Visual/Verbal & -4 & 6 & 1,5 & 1,1 & 3,5 \\
Sequencial/Global & -3 & 7 & 2,5 & 2,2 & 3,4 \\
\hline
\end{tabular}

O uso do ILS permitiu identificar uma tendência maior por parte dos alunos a serem ativos, visuais, sensoriais e sequenciais, assim como o professor. Porém, observou-se que o professor possui uma característica um pouco distinta dos alunos em relação às preferências, classificadas como forte em todas as dimensões analisadas. Com base no questionário do ILS, percebeuse compatibilidade entre o professor e os estilos de aprendizagem dos alunos. Sendo assim, considera-se fundamental aplicar-se o ILS no primeiro dia de aula para futuras correções de metodologias docentes, pois pode haver uma incompatibilidade entre o perfil do professor e o estilo de aprendizagem dos alunos. Com esse conhecimento prévio o professor poderá adequar a sua aula e assim fazer o uso de recursos didáticos, como por exemplo, os jogos, a fim de facilitar a aprendizagem em sala.

Silva Junior et al. (2013) observaram que quando há incompatibilidade entre as preferências de aprendizagem dos alunos e dos professores, os resultados do ILS podem auxiliar no planejamento das atividades de ensino/aprendizagem e evitar possíveis problemas ao longo das disciplinas lecionadas.

\subsection{Quanto à avaliação do emprego do jogo}

Na segunda etapa da avaliação, foi aplicado outro questionário, realizado após o fim do jogo. A frequência das respostas foi quantificada e tirada uma média para cada aspecto analisado $(a, b$, c, d) e um resumo simples das respostas foi realizada através de uma análise descritiva utilizando medidas de tendência e variabilidade como média, mediana, desvio padrão e o valor máximo e mínimo dos dados obtidos em cada nível de satisfação (péssimo, ruim, regular, bom e ótimo). Como observado na Tabela 4, a maior parte das respostas dadas pelos alunos variou entre bom e ótimo, indicando que a atividade teve boa receptividade pela turma.

Tabela 4: Estatística das respostas dos alunos para o questionário de avaliação do jogo

\begin{tabular}{llllll}
\hline Aspectos analisados no jogo & Péssimo & Ruim & Regular & Bom & Ótimo \\
\hline (a) Motivação & - & $6,7 \%$ & $23,3 \%$ & $40,0 \%$ & $30,0 \%$ \\
(b) Aprendizagem & - & - & $30,0 \%$ & $33,3 \%$ & $36,7 \%$ \\
(c) Processamento e armazenamento & - & - & $16,7 \%$ & $53,3 \%$ & $30,0 \%$ \\
do conhecimento & - & $6,7 \%$ & $20,0 \%$ & $56,7 \%$ & $16,7 \%$ \\
(d) Habilidades & 0 & 0 & 10 & 30 & 0 \\
\hline Mínimo & 0 & 20 & 40 & 80 & 60 \\
Máximo & 0 & 0 & 20 & 40 & 30 \\
Mediana & 0 & 3,3 & 22,5 & 45,8 & 28,3 \\
Média & 0 & 6,5 & 9,6 & 16,7 & 19,0 \\
Desvio Padrão & & & &
\end{tabular}

As respostas favoráveis dadas para o aspecto da motivação, cerca de $70 \%$, indicam que o jogo estimula e aguça o interesse pela disciplina na maioria dos alunos. Para Silva (2005) e Tapia e Fita (2015), a motivação escolar não é algo simples de se obter e o uso do jogo em sala pode ser utilizado como recurso de motivação para aprendizagem, pois o professor desenvolve aulas mais atrativas, divertidas e a aprendizagem acaba por acontecer simultaneamente. 
Quanto à análise das respostas relativas ao item aprendizagem, 70\% dos alunos acreditam que a sua aprendizagem foi satisfatória durante o jogo e $30 \%$ que a sua aprendizagem foi regular. 0 professor precisa viabilizar meio e mecanismo que possam proporcionar condições favoráveis para a aprendizagem do aluno e o jogo pode auxiliar nesse processo, sendo uma fonte que facilita a aprendizagem (Alves e Bianchin, 2010).

Quanto ao item processamento e armazenamento do conhecimento, 83\% acreditam que o uso do jogo como ferramenta de ensino auxilia no armazenamento do conhecimento adquirido em sala de aula. Os jogos aumentam as possibilidades de aprendizagem do aluno em sala, pois estimulam formas diferentes para que ocorra o processamento e armazenamento do conhecimento. Os alunos tendem a melhor armazenar o conhecimento com a utilização dos jogos se comparado com as aulas tradicionais expositivas (De Melo, 2012).

Quando um aluno de Engenharia Civil se gradua, espera-se que possua competências e habilidades fundamentais para a sua profissão. Observou-se que algumas dessas habilidades foram exploradas durante o jogo, com o objetivo de auxiliar a formação, dentre elas: identificar, formular e resolver problemas de engenharia; aplicar conhecimentos matemáticos, científicos, tecnológicos e instrumentais à engenharia; comunicar-se eficientemente e atuar em equipe. Segundo as respostas dos alunos, $74 \%$ disseram que o desenvolvimento dessas habilidades no jogo se deu entre bom e ótimo, 20\% de forma regular e $7 \%$ de maneira ruim.

Outra forma de avaliar o jogo como uma ferramenta de auxílio ao ensino se deu através da análise das notas obtidas pelos alunos nas provas aplicadas durante a disciplina de Materiais Betuminosos. Foram realizadas duas provas durante toda a disciplina e a aplicação do jogo se deu antes da realização da segunda prova. Em uma escala de 0 a 10, a média das notas de desempenho dos alunos na primeira avaliação em que não houve a utilização do jogo foi de 6,5, enquanto que na segunda avaliação, onde houve a aplicação do jogo como auxílio ao ensino, a média das notas foi de 8,0. Embora seja necessária uma base maior de dados, observou-se o potencial do o uso do jogo ser um recurso didático em sala de aula que pode contribuir no processo de ensino e aprendizagem. Trabalhos anteriores já apresentaram também resultados bastante promissores. Souza-Lomba et al. (2010) fizeram aplicação de dois questionários, ambos com as mesmas questões para verificar a assimilação do tema abordado antes e após a aplicação do jogo intitulado "Jogando Limpo". Em todas as questões houve o aumento da assimilação do tema por parte dos alunos, chegando a $100 \%$ de acertos em quase todas as questões após o uso do jogo. Lima e Melo (2013) aplicaram um questionário adaptado de Savi et al. (2010) para avaliação dos jogos educativos utilizados em sala, sendo que 83,7\% dos alunos concordaram que os jogos facilitaram lembrar das informações relacionadas aos temas abordados nos jogos e 75,2\% concordaram que se sentiram estimulados em aprender com o jogo. García et al. (2017) apresentaram resultados em que $94,3 \%$ dos alunos validaram o uso do jogo chamado de "Projeto Ponto de Partida" como uma atividade pertinente e relevante a ser inserida em uma disciplina de graduação para a disseminação de conhecimento. Assim, conforme as referências citadas, o presente estudo aponta que o jogo é uma iniciativa didática com potencial metodológico, além de proporcionar diversão e interação entre os alunos.

\section{CONSIDERAÇÕES FINAIS}

Este trabalho apresentou uma metodologia aplicada em sala de aula, com o uso de um jogo de tabuleiro, que contribuiu para o aprimoramento do ensino e da aprendizagem na disciplina de Materiais Betuminosos do curso de graduação de Engenharia Civil da UFC. Ainda que por meio 
de um estudo de caso simples, os resultados apontam a importância da utilização de aulas diferenciadas na construção de um ambiente alegre e capaz de despertar a vontade dos alunos de aprender brincando. A proposta do uso de jogos é um instrumento didático e a sua implementação deve ser considerada uma alternativa complementar ao ensino em sala de aula. Com base nas respostas atribuídas nos questionários idealizados, foi possível perceber o potencial do jogo em proporcionar motivação, aprendizagem, armazenamento do conhecimento e o desenvolvimento de algumas habilidades inerentes a um profissional da área de Engenharia Civil. Verificou-se, também, que os jogos proporcionam diversão aliada à interação entre os estudantes e o professor, e possibilitam a complementação do aprendizado. Como continuação do trabalho, pretende-se aplicar o jogo em mais turmas da mesma disciplina e em outras disciplinas relacionadas à Engenharia de Transportes, como as de Projeto e Construção da Infraestrutura Viária e Projeto e Construção da Superestrutura Viária, com as devidas alterações de acordo com as características e necessidades de cada disciplina.

\section{REFERÊNCIAS}

Alves, L. e M. A. Bianchin (2010) O Jogo Como Recurso de Aprendizagem. Revista Psicopedagogia. São José do Rio Preto - SP, v. 27, n. 83, p. 282-287. ISSN 282-287.

Ammar, S. e R. Wright (1999) Experiential Learning Activities in Operations Management. International Transactions in Operational Research, v. 6, n. 2, p. 183-197. DOI: 10.1111/j.1475-3995.1999.tb00150.x.

$\mathrm{Au}, \mathrm{T}$;; R. Bostleman e E. Parti (1969) Construction Management Game - Deterministic Model. Jornal of the Construction Division, ASCE, v. 95, n. 1, p. 25-38.

Baker, A.; E. O. Navarro e A. van der Hoek (2005) An Experimental Card Game for Teaching Software Engineering Processes. Journal of Systems and Software, v.75, p. 3-16. DOI:10.1016/j.jss.2004.02.033.

Balceiro, L. B.; R. M. Naveiro e H. V. MEDINA (2003) A Criação de um Jogo Pedagógico para Apoio ao Ensino de Engenharia. Anais do XXXI Congresso Brasileiro de Educação em Engenharia, COBENGE, Rio de Janeiro v. 1. p. 1-8.

Belhot, R. V.; A. A. Freitas e D. V. Dornellas (2005) Benefícios do Conhecimento dos Estilos de Aprendizagem no Ensino de Engenharia de Produção. XXXIII Congresso Brasileiro de Educação em Engenharia, COBENGE, Campina Grande - PB.

Braga, A. J.; M. M. Araújo; S. R. S. Vargas e A. Lemes (2007) Uso dos Jogos Didáticos em Sala De Aula. X Seminário Intermunicipal de Pesquisa; VIII Salão de Iniciação Científica e Trabalhos Acadêmicos e V Mostra de Atividades Extensionistas e Projetos Sociais. Universidade Luterana do Brasil, Unidade Guaíba. Tema Cultura e Diversidade.

Braghirolli, L. F. (2014) Aprendizagem por Jogo Computacional na Engenharia de Produção. Tese de Doutorado - Programa de Pós-Graduação em Engenharia de Produção da Universidade Federal do Rio Grande do Sul. Porto Alegre - RS.

Cury, H. N. (2000) Estilos de Aprendizagem de Alunos de Engenharia. XXVIII Congresso Brasileiro de Educação em Engenharia, COBENGE, Ouro Preto - MG.

De Melo, I. R. P. (2012) O uso de jogos eletrônicos como ferramenta de ensino: um estudo da suíte de jogos GCOMPRIS. Trabalho de Conclusão de Curso - Universidade Federal do Amapá. Macapá - AP.

Felder, R. M. e B. A. Soloman (1991) Index of Learning Styles (ILS).

Felder, R. M. e L. K. Silverman (1988) Learning and Teaching Styles in Engineering Education. Engineering Education, v. 78, n. 7, p. 674-681. ISSN 674-681.

García, D. S. P.; A. T. Nodari; J. F. Albano; M. C. Wandscheer; F. F. F. Dos Santos; C. L. Andriola; C. P. Demore e T. K. Lanes (2017) Projeto Ponto de Partida: O Ensino de Projetos de Rodovias Através de Uma Abordagem Lúdico-Real-Didática. Revista Transportes, Rio de Janeiro, v. 25, n. 3, p. 135-165. D0I:10.14295/transportes.v25i3.1327.

Kuri, N. P. (2004) Tipos de Personalidade e Estilos de Aprendizagem: Proposições para o Ensino de Engenharia. Tese (Doutorado). Universidade Federal de São Carlos. São Carlos.

Kuri, N. P.; A. N. Rodrigues da Silva e M. A. Pereira (2006) Estilos de Aprendizagem e Recursos da Hipermídia Aplicados no Ensino de Planejamento de Transportes. Revista Portuguesa de Educação, 2006, v. 19, n. 2, p. 111-137. ISSN 111-137.

Lane, D. (1995) On a Resurgence of Management Simulations and Games. Journal of the Operational Research Society, v. 46, n. 5, p. 604-625. DOI:10.1057/jors.1995.86.

Lima, C. D. A e R. A. Melo (2013) Jogos Educativos para Estradas e Transportes. Anais do XXVII ANPET - Congresso de Pesquisa e Ensino em Transporte, ANPET, Rio de Janeiro, v.1, p. 1-12.

MEC - Ministério da Educação (2001) Diretrizes Curriculares Nacionais para os Cursos de Engenharia. Parecer CES 1.362/2001, homologação publicada no DOU 25/02/2002, Seção 1, p. 17. Resolução CES/CNE 11/2002, publicada no DOU 09/04/2002, Seção 1, p. 32. Brasília - DF.

Ozelkan, E. e A. Galambosi (2010) Lampshade Game for Lean Manufacturing. Production Planning \& Control: The Management of Operations, v. 20, n. 5, p. 385-402. DOI:10.1080/09537280902875419. 
Pereira, M. A. (2005) Ensino-Aprendizagem em um Contexto Dinâmico: O Caso de Planejamento de Transportes. Tese (Doutorado). Escola de Engenharia de São Carlos - USP. São Carlos.

Pereira, M. A.; N. P. Kuri e A. N. Rodrigues da Silva (2004) Os Estilos de Aprendizagem e o Ensino de Engenharia de Transportes. XVIII Congresso de Pesquisa e Ensino em Transportes, ANPET, Florianópolis, v.1, p. 1529-1540.

Sacks, R.; A. Esquenazi e M. Goldin (2007) LEAPCON: Simulation of Lean Construction of High-Rise Apartment Buildings. Journal of Construction engineering and management, v. 133, n. 7, p. 529-539. DOI:10.1061/(ASCE)07339364(2007)133:7(529).

Savi, R.; C. G. V. Wangenheim; V. R. Ulbricht e T. Vanzin (2010) Proposta de um Modelo de Avaliação de Jogos Educacionais. RENOTE. Revista Novas Tecnologias na Educação, v. 8, n. 3, p. 1-10. ISSN 1679-1916.

Silva Junior, C. A. P.; H. B. Fontenele e A. N. R. Da Silva (2013) Estilo de ensino versus estilos de aprendizagem no processo de ensino aprendizagem: uma aplicação em Transportes. Revista Transportes, v. 21, n 2, p. 30-37. DOI:10.4237/transportes.v21i2.686.

Silva, M. S. (2005) Clube da matemática: Jogos Educativos (2ª ed). Editora Papirus, Campinas - SP.

Silveira, S. R. e D. A. C. Barone (1998) Jogos Educativos Computadorizados Utilizando a Abordagem de Algoritmos Genéticos. IV RIBIE - Congresso da Rede Iberoamericana de Informática Educativa, Brasília, p. 1-13.

Siqueira, A. M. O.; A. L. M. F. Feijó; L. H. F. Prates e G. M. C. Pereira (2013) Estilos de Aprendizagem e Estratégias de Ensino em Engenharia. Eleventh LACCEI Latin American and Caribbean Conference for Engineering and Technology, Cancun, México.

Siqueira, A. M. O.; L. H. F. Prates; I. O. D. Paula; A. O. Andrade e W. R. M. Araújo (2012) Estilos de Aprendizagem e Estratégias de Ensino em Engenharia. XL Congresso Brasileiro de Educação em Engenharia, COBENGE, Belém - PA.

Soares, M. H. F. B. (2008) Jogos e Atividades Lúdicas no Ensino de Química: Teoria, Métodos e Aplicações. XIV Encontro Nacional De Ensino De Química, ENEQ, Curitiba.

Song, Q.; L. He e X. Hu (2012) To Improve the Interactivity of the History Educational Games with Digital Interactive Storytelling. Physics Procedia, n. 33, p. 1798-1802. ISSN 1875-3892.

Souza-Lomba, F. C. M.; T. R. Assis; F. G. Costa; G. M. L. Martins e F. C. Frasson-Costa (2010) Avaliação da Aprendizagem por Meio do Jogo Didático "Jogando Limpo", nas Aulas de Ciências. 2º CIEPG - Congresso Internacional de Educação, Ponta Grossa, p. 1-14.

Tapia, J. A. e E. C. Fita (2015) A Motivação em Sala de Aula: O Que é, Como Se Faz (11ª ed). Editora Loyola, São Paulo.

Vasconcelos, E. S.; J. P. Silva; T. S. Moreira; K. L. Cézar; M. L. B. Santos e J. G. F. Lorenzo (2012) Jogos: uma forma lúdica de ensinar. Anais do VII Congresso de Pesquisa e Inovação da Rede Norte Nordeste de Educação Tecnológica, CONNEPI, Palmas.

Verschueren, F. e N. Mardjan (2015) Educational Gaming is an Inspirational New Possibility for Authentic Learning. Physiotherapy, v. 101, n. 1, p. 1588-1589. DOI:10.1016/j.physio.2015.03.1595.

Zanon, D. A. V.; M. A. S. Guerreiro e R. C. Oliveira (2008) Jogo Didático Ludo Químico Para o Ensino de Nomenclatura dos Compostos Orgânicos: Projeto, Produção, Aplicação e Avaliação. Ciências \& Cognição, Rio de Janeiro, v. 13, n. 1, p. 72-81. ISSN 1806-5821. 